\title{
Management of palatal fistulas and a simple surgical algorithm proposal
}

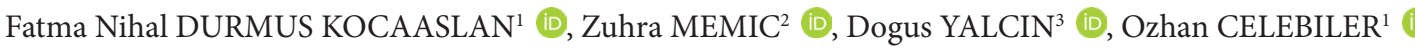 \\ Department of Plastic, Reconstructive and Aesthetic Surgery, School of Medicine, Marmara University, Istanbul, Turkey. \\ Plastic, Reconstructive and Aesthetic Surgery Clinic, Klinika Varis, Sarejova, Croatia. \\ Plastic, Reconstructive and Aesthetic Surgery, Private Practice, Istanbul, Turkey.
}

Corresponding Author: Fatma Nihal DURMUŞ KOCAASLAN

E-mail: dr-nihal@hotmail.com, fatmanihald7@gmail.com

Submitted: 04.10.2019 Accepted: 27.11.2019

\begin{abstract}
Objectives: Despite improved techniques in repair of cleft palate, failure of healing of palatal structures resulting in a palatal fistula is one of the major challenges in the practice of reconstructive surgery. The aim of this study is to evaluate treatment success and failure in patients with palatal fistulas following cleft palate repair.

Patients and Methods: Totally 44 patients with a history of cleft palate who underwent surgery for palatal fistula were included in this study undertaken between January 1999 and August 2014. Fistulas were classified as anterior and posterior according to the repair technique and were repaired using one of the following techniques: buccal mucosal flap, tongue flap or mucoperiosteal flap.

Results: Success rate for anterior fistulas was $71.42 \%$ with tongue flap and $76.92 \%$ with mucoperiosteal flap. Success rate for posterior fistulas was $84.62 \%$ with mucoperiosteal flap and $75 \%$ with buccal mucosal flap. Difference in success rates between the anterior and posterior fistulas was not statistically significant.

Conclusion: Our study results suggest the use of mucoperiosteal flaps for both anterior and posterior fistulas smaller than $5 \mathrm{~mm}$ as the first choice, guided by the principle of replacing absent tissue with similar tissue.

Keywords: Cleft palate, Palatal fistula, Post-palatoplasty fistula, Tongue flap, Two-flap palatoplasty.
\end{abstract}

\section{INTRODUCTION}

Despite improved techniques in repair of cleft palate, failure of healing of the palatal structures resulting in a palatal fistula is one of the major challenges in the practice of plastic and reconstructive surgery which prevents favorable outcomes in cleft palate repair. The formation of a post-palatoplasty fistula has been shown to be associated with the severity and the type of cleft, the repairing technique, timing of the repair, experience of the surgeon, tension at the suture site, hemorrhage, infection, postoperative anemia, and lack of postoperative follow-up [1-3].

The main goal of cleft palate repair is to allow for speech development and dental hygiene without disturbing midface development. Accordingly, cleft palate repair is usually performed in the first year of life before the child starts to speak. A palatal fistula, which occurs in 4 to $25 \%$ of cases, is a complication of cleft palate repair [4-10]. The indications for a fistula repair depend on the related symptoms. The most common symptoms include nasal emission causing speech distortions, leakage of fluid and food into the nasal cavity leading to poor oral hygiene, and foul smell. It is wellestablished that fistulas causing speech disturbances should be repaired as soon as possible, while small fistulas which do not affect speech with occasional regurgitation of fluid/food into nose can be delayed [11].

Until now, several attempts have been made for the classification of palatal fistulas according to the site $[1,12,13]$. Classification of fistulas based on the difficulty index has been proposed to help in preoperative management of the outcomes [13]. Initially, palatal fistulas were classified as anterior, middle (i.e., at the junction of the soft and hard palate), and posterior. [2]. In a series of 64 patients, the hard-soft palate junction was the most common site (53.1\%) [14].

Although, palatal fistulas are common morbidities following cleft palate repair, there is no established treatment algorithms. In the present study, we aimed to evaluate treatment success and failure in patients with palatal fistulas following cleft palate repair. 


\section{PATIENTS and METHODS}

This retrospective study was conducted at the Department of Plastic, Reconstructive and Aesthetic Surgery, Marmara University Training and Research Hospital, between January 1999 and August 2014. A total of 51 patients with a prior history of cleft palate underwent surgery for palatal fistulas. Exclusion criteria were as follows: having a fistula following tumor surgery; having a traumatic fistula; asymptomatic fistulas and being lostto-follow-up. Finally, a total of 44 patients who were operated for a palatal fistula following cleft palate repair were included in the study. A written informed consent was obtained from each patient. The study was reviewed and approved by the Marmara University, School of Medicine Ethics Committee (protocol number: 952). The study was conducted in accordance with the principles of the Declaration of Helsinki. Data regarding demographic and clinical characteristics of the patients including age, sex, primary cleft type, technique of primary repair, age at primary closure, symptoms, size, location, age at fistula repair, type of fistula repair, velopharyngeal function, orthodontic treatment, and outcome were retrospectively retrieved from the hospital archives. In addition, local tissue availability, scar tissue formation, inflammation, oral hygiene, and other surgical procedures were evaluated to select the most appropriate fistula repair technique. Pre-, intra-, and postoperative images were also evaluated.

In the present study, palatal fistulas were classified as anterior and posterior based on repair technique, and a fistula at the hard-soft palate junction was considered a posterior fistula.

\section{Surgical techniques}

Palatal fistulas were repaired by one of the following techniques: Buccal mucosal flap, tongue flap and mucoperiosteal flap.

\section{Buccal mucosal flap}

The buccal mucosal flap, originally described in 1969 by Mukherji as a cheek flap, is used in primary palatoplasty [15]. This technique is particularly advantageous, when the fistula is localized at the hard-soft palate junction. The buccal mucosal flap is a posteriorly based random pattern flap, and its base is located near the retromolar trigone. The distal end of the flap is located slightly below the oral commissure, and one structure which requires particular care during flap harvesting is the papilla of the parotid duct. The flap, if necessary, can be harvested from both sides and can be used both for the oral and nasal layer closure. The part of the buccinator muscle can be also incorporated in the flap to make it more robust. In that case, the flap is called a buccinator myomucosal flap [16].

\section{Tongue flap}

This is a two-stage procedure. The use of the lingual tissue in palatal fistula repair was reported more than five decades ago by Santos and Altamirano [17]. It has been shown that this technique is safe and well-tolerated by children, when applied properly. The flap is indicated for larger fistulas where there is a significant tissue deficit in the oral mucoperiosteal layer. The flap can be anteriorly or posteriorly located, depending on the site of the fistula. In our study, we used an anteriorbased tongue flap. A good nasal layer repair was necessary for the treatment success. Detachment was done at the fourth postoperative week (Figure 1,2). The donor area was almost always closed primarily.

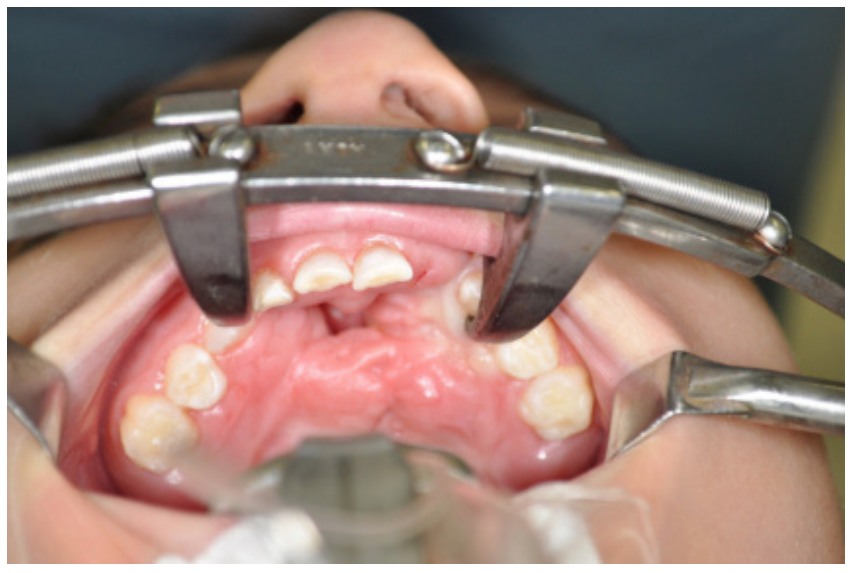

Figure 1. Anterior palatal fistula

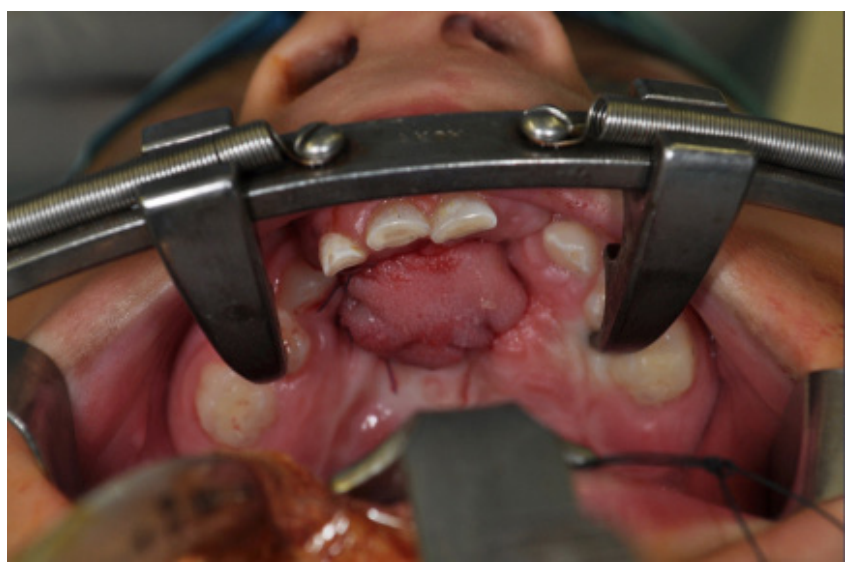

Figure 2. A tongue flap was used for an anterior fistula.

\section{Mucoperiosteal flap}

If the small or medium-sized fistulas were localized asymmetrically and anteriorly, a C-shaped mucoperiosteal flap was elevated around the fistula and used to achieve the nasal layer. The flap was elevated on the other side and rotated over the defect to create the oral layer (Figure 3,4). The required rotation flap could be larger than expected. Alternatively, if the fistula was localized at the junction or at the soft palate, the incisions were made around the fistula and turned inside and sutured together to achieve the nasal closure. Then, bilateral unipedicled (two-flap palatoplasty technique) or bipedicled mucoperiosteal flaps (Von Langenbeck) were elevated, advanced toward the middle, and sutured together (Figure 5, 6). 


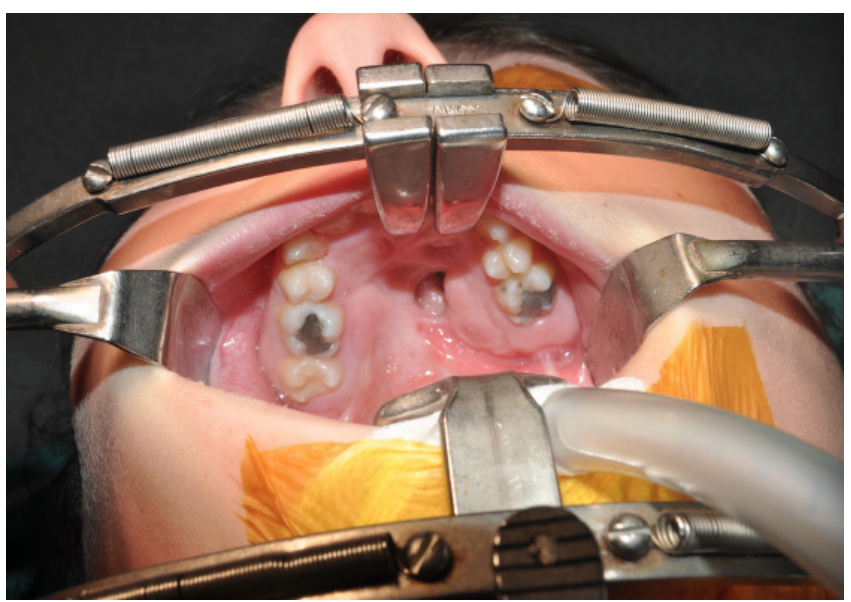

Figure 3. Palatal fistula on the hard palate

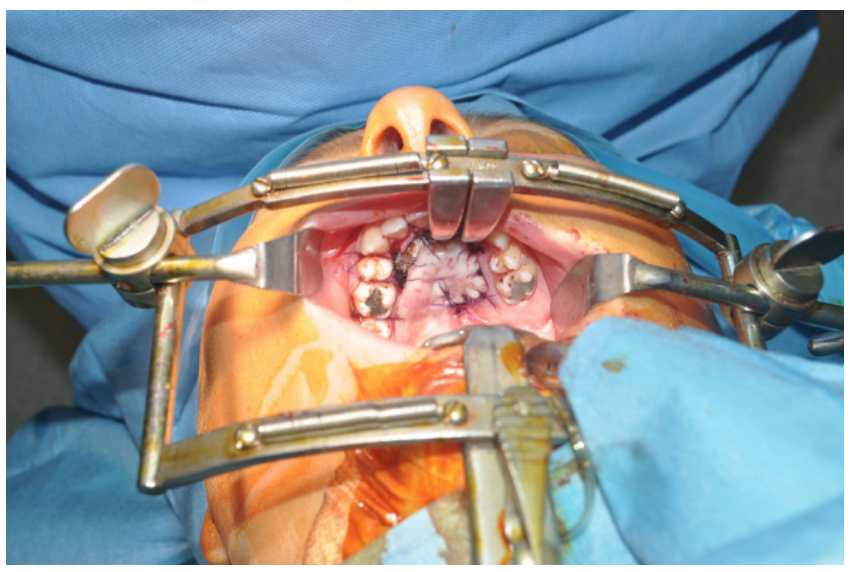

Figure 4. A rotation flap was transposed to cover the defect.

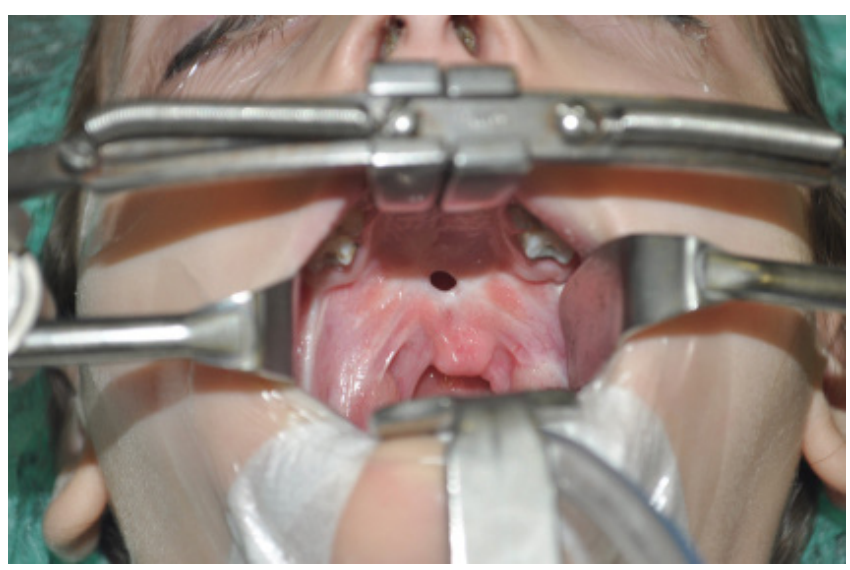

Figure 5. Fistula on the soft palate

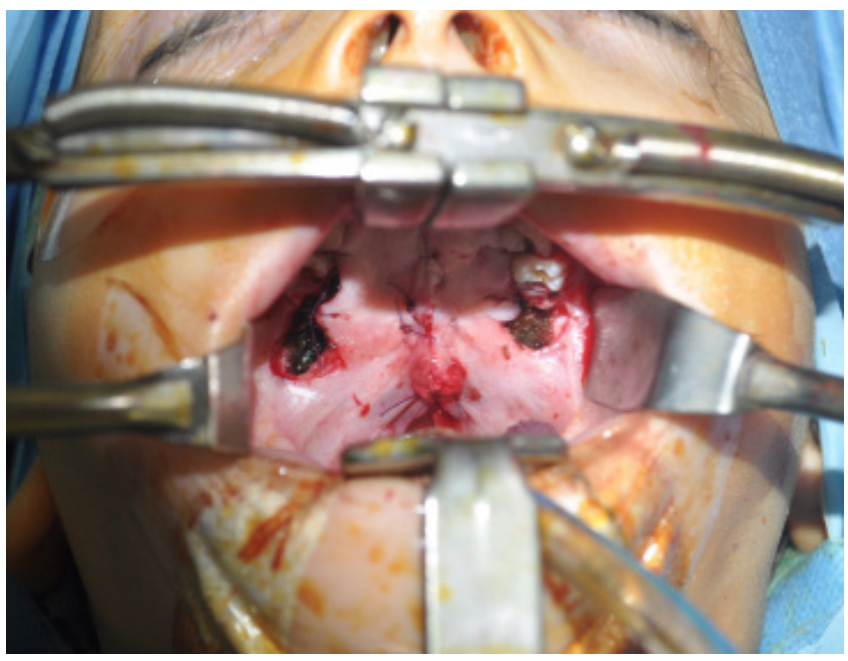

Figure 6. Bipedicled flap was advanced to cover the defect.

\section{Statistical Analysis}

Statistical analysis was performed using the GraphPad Prism software (GraphPad Software Inc., CA, USA). Descriptive data were expressed in mean \pm standard deviation (SD), median (min-max), or number and frequency. The Fisher's exact test was used for statistical analysis. A P value of $<0.05$ was considered statistically significant.

\section{RESULTS}

Of all patients, 22 were males and 22 were females. The mean age was 14.3 (range, 5 to 32) years. The mean age at the time of the first repair was 19.3 (range, 9 to 120) months. The mean age at the time of fistula repair was 7.7 (range, 4 to 29) years. The mean follow-up was 5.4 (range, 2 to 7 ) years. Demographic and clinical characteristics of the patients are shown in Table I.

Table I. Demographic and clinical characteristics of patients

\begin{tabular}{|c|c|c|}
\hline & & \\
\hline & $\mathrm{n}$ & $\%$ \\
\hline Sex & & \\
\hline Female & 22 & $50 \%$ \\
\hline Male & 22 & $50 \%$ \\
\hline Cleft type & & \\
\hline Isolated cleft palate & 16 & $36.4 \%$ \\
\hline Unilateral cleft lip and palate & 12 & $27.2 \%$ \\
\hline Bilateral cleft lip and palate & 16 & $36.4 \%$ \\
\hline Fistula localization & & \\
\hline Anterior & 27 & $61.4 \%$ \\
\hline Posterior & 17 & $38.6 \%$ \\
\hline
\end{tabular}


The most common types of cleft were bilateral cleft lip and palates $(n=16,36.4 \%)$ and isolated cleft palates $(n=16,36.4 \%)$. Unilateral complete cleft lip and palate was seen in 12 patients (27.2\%). The mean fistula size was 1.12 (range, 0.8 to 1.5 ) $\mathrm{mm}$ for anterior fistulas which were repaired with a tongue flap and 0.4 (range, 0.3 to 0.5 ) $\mathrm{mm}$ for anterior fistulas which were repaired with a mucoperiosteal flap. The mean fistula size was 0.85 (range, 0.7 to 1$) \mathrm{mm}$ for posterior fistulas which were repaired with a buccal mucosal flap and 0.4 (range, 0.3 to 0.5 ) $\mathrm{mm}$ for posterior fistulas which were repaired with a mucoperiosteal flap.

The number of the patients with an anterior fistula was 27 (61.4\%). Among these, 14 patients (31.8\%) underwent tongue flap surgery and 13 patients $(29.5 \%)$ underwent mucoperiosteal flap reconstruction. Successful outcomes were obtained in $71.42 \%(10 / 14)$ of the patients with tongue flap and $76.92 \%$ $(10 / 13)$ of the patients with mucoperiosteal flap. (Figure 3). There was no statistically significant difference in the success rate according to the operation technique (tongue flap versus mucoperiosteal flap) in the anterior fistula group ( $p>0.05)$. The number of the patients who developed a posterior fistula was $17(38.6 \%)$. In $13(29.5 \%)$ of them, mucoperiosteal flap was performed and four $(9.1 \%)$ underwent buccal mucosal flap surgery. Successful outcomes were obtained in $84.6 \%(11 / 13)$ of the patients with mucoperiosteal flap and $75 \%(3 / 4)$ of the patients with buccal mucosal flap (Figure 4). There was no statistically significant difference in the success rate according to the operation technique in the posterior fistula group $(\mathrm{p}>0.05)$

(Table II).

Table II. Failure and success rates according to the operation technique

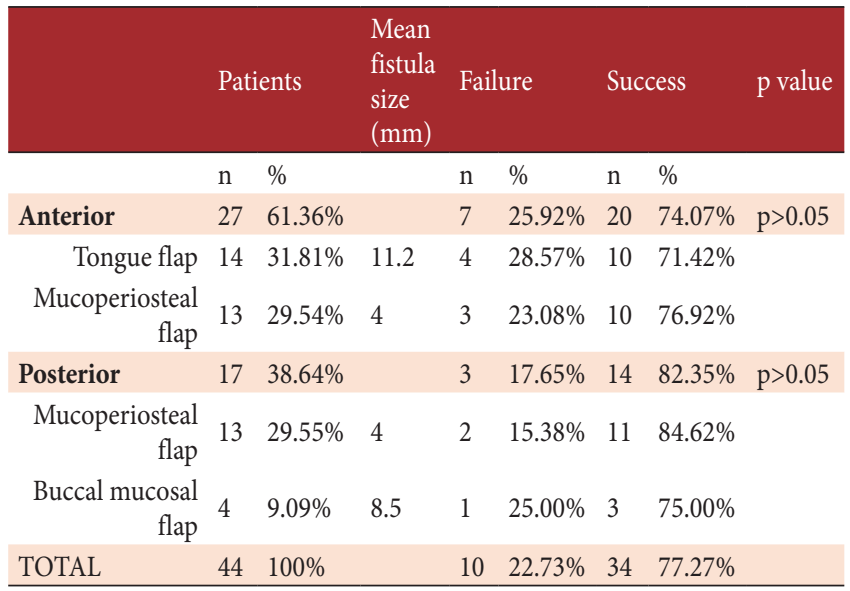

The overall surgical success rate was $77 \%$ (34/44), with fistulas remaining in $23 \%(10 / 44)$ of the patients. All four of 14 patients who were treated with a tongue flap and failed were younger than six years. The failure patient group who were repaired with a mucoperiosteal flap or buccal mucosal flap had no similar history. There was no syndromic patient in the present study. The patients who were unresponsive to these treatments were reevaluated for next operations at least one year later (data not shown).

\section{DISCUSSION}

In the present study, we evaluated treatment success and failure in patients with palatal fistulas following cleft palate repair. Our study results showed that the surgical technique applied in our facility yielded comparable outcomes with the previous findings reported in the literature.

Palatal fistula is the most common complication of cleft palate surgery and fistula formation may occur even with the best hand. In the literature, recurrence rate following palatal fistula closure has been reported as $25 \%$ to $33 \%$ [1]. As the risk of fistula formation increases with every failure, all attempts should be made for successful palate repair during the first surgery.

Oronasal fistulas, which mainly demonstrate nasal regurgitation and speech problems, occur in 4 to $35 \%$ of cases [1]. Previous studies have shown that the incidence of oronasal fistulas ranges from 5 to $60 \%(1,2,18,19)$. A meta-analysis of 11 studies involving 2.505 children reported that the rate of fistula formation following primary palatal surgery was $4.9 \%$ [3]. In our study, the clinical rate of fistula formation was $6.76 \%$ during a 15-year study period.

The variety of surgical techniques indicates the lack of consensus on the optimal treatment technique in palatal fistulas. Repair of palatal fistula is a challenging procedure for cleft palate surgeons. Using intraoral flaps rather than external flaps has been reported to be associated with fewer donor site problems [16]. In a study investigating applications in intraoral reconstruction using three different techniques, Bianchi et al., reported that buccinator flaps were a good choice for the reconstruction of mid-sized oral cavity defects with a complication rate of $7 \%$, which is not consistent with our findings [16]. In this study, although the number of repairs with the buccal mucosa flap was low, the complication rate was about $25 \%(1 / 4)$.

In the present study, there was a significant correlation between the anterior fistula occurrence and bilateral cleft palate. Bukowski et al., reported that patients with complete bilateral clefts (Veau IV classification) were more likely to develop a fistula [3]. Similarly, Phua et al., reported that anterior fistulas were more common in patients with a bilateral cleft lip and complete cleft palate [5].

Due to previous cleft palate repair, scar formation on the mucoperiosteal flap area makes this technique complicated for closure $(2,20,21)$. Muzaffar et al., reported a success rate of $67 \%$ [2]. However, Cohen et al., reported a success rate of $33 \%$ in their study [1]. On the contrary, Emory et al., achieved successful results in $91 \%$ of cases [19]. In the present study, mucoperiosteal flaps were used for fistulas less than $5 \mathrm{~mm}$, the success rate with this technique was $76.92 \%$ for anterior fistulas and $84.62 \%$ for posterior fistulas.

The tongue flap can be used to treat large anterior fistulas without causing any donor site problems. A donor site scar is acceptable, if there is no limitation on the tongue mobility or taste sensation [22]. However, the main disadvantage of this technique is that it is a two-stage procedure with possible intubation and extubation problems and impaired quality of 
life between the procedures. In addition, age is another factor which precludes to achieve successful results in young cases. Our findings demonstrated that using a tongue flap was a safe and effective method of treatment for large fistulas greater than $5 \mathrm{~mm}$ with a success rate of $71.42 \%$.

A posterior fistula is more commonly related to syndromic causes. Most cases less than $5 \mathrm{~mm}$ can be closed with a mucoperiosteal flap, greater than $5 \mathrm{~mm}$ can be closed with posterior based buccal mucosal flaps. But in patients with a very large fistula, free flap transfer is recommended. However, compared to other surgical techniques, free flaps require prolonged duration of surgery and hospitalization and may lead to donor site morbidities. In the present study, none of our patients were treated with free tissue transfer. Furthermore, many surgeons use adjunctive therapies such as dermis or other barriers during fistula repair [22,23]. In the present study, however, no foreign materials or autologous dermal tissues were used.

In the literature, fistulas are often classified into three localizations: hard palate, soft palate, and junction of the hard and soft palate. Where applicable, it is recommended to repair symptomatic fistulas with mucoperiosteal flaps and large fistulas with tongue flap versus free flaps [24]. In our study, we mainly classified fistulas as anterior and posterior. Posterior fistulas include the soft palate and junction area with similar closure techniques. This algorithm simplifies the decision-making process.

Despite satisfactory cleft palate repair outcomes, the main limitations of the present study include its small sample size and retrospective design which precludes establishing a novel treatment algorithm for this patient population. In addition, in our study, we mainly classified palatal fistulas as anterior and posterior, and the fistulas located at the hard-soft palate junction were also considered posterior fistulas. Therefore, further large-scale and long-term prospective studies with a thorough classification are needed to draw a definite conclusion.

\section{Conclusion}

In conclusion, although not statistically significant, the success rate was significantly higher for tongue flap and mucoperiosteal flap in the anterior fistula group. Based on our study results, we suggest that mucoperiosteal flaps can be used for both posterior and anterior fistulas as the first choice, guided by the principle of replacing tissue with similar tissue with low failure and low morbidity rates. If the palatal tissues are not available, the tongue flap for anterior fistulas and buccal mucosal flap for posterior fistulas are preferred. Although, further studies are still needed, we believe that surgical techniques to gain a better understanding of developmental anatomy are valuable.

\section{Compliance with Ethical Standards}

Ethical approval: The study was reviewed and approved by the Marmara University, School of Medicine Ethics Committee (protocol number: 952). The study was conducted in accordance with the principles of the Declaration of Helsinki.
Funding: The study was not supported by any funds.

Conflict of interest: The authors declare that they have no conflict of interest.

Informed consent: A written informed consent was obtained from each participant.

\section{REFERENCES}

[1] Cohen SR, Kalinowski J, LaRossa D, Randall P. Cleft palate fistulas: A multivariate statistical analysis of prevalence, etiology, and surgical management. Plast Reconstr Surg 1991;87:1041-7.

[2] Muzaffar AR, Byrd HS, Rohrich RJ, Johns DF, LeBlanc D, Beran SJ, et al. Incidence of cleft palate fistula: an institutional experience with two-stage palate repair. Plast Reconstr Surg 2001;108:1515-8

[3] Bykowski MR, Naran S, Winger DG, Losee JE. The rate of oronasal fistula following primary cleft palate surgery: A meta analysis. Cleft Palate Craniofac J 2015;52:81-7. doi: 10.1597/14-127.

[4] Andersson E-M, Sandvik L, Semb G, et al. Palatal fistulas after primary repair of clefts of the secondary palate. Scand J Plast Reconstr Surg Hand Surg 2008;42:296-9. doi: 10.1080/028.443.10802299676.

[5] Phua YS, de Chalain T. Incidence of oronasal fistulae and velopharyngeal insufficiency after cleft plate repair: An audit of 211 children born between 1990 and 2004. Cleft Palate Craniofac J 2008;45:172-8. doi: 10.1597/06-205.1.

[6] Farzaneh F1, Lindman R, Becker M, Hansen K, Svensson H. Von Langenbeck procedures at 14 months or Wardill at 18 months for primary repair of cleft palate in adult Swedish patients with bilateral complete cleft lip and palate: A study of facial growth. Scand J Plast Reconstr Surg Hand Surg 2009;43:214-24. doi: 10.1080/028.443.10903040789.

[7] Lu Y, Shi B, Zheng Q, et al. Incidence of palatal fistula after palatoplasty with levator veli palatine retropositioning according to Sommerland. Br J Oral Maxillofac Surg 2010;48:637-40. doi: 10.1016/j.bjoms.2009.10.018.

[8] Landheer JA, Breugmen CC, Mink van der Molen AB. Fistula incidence and predictors of fistula occurrence after cleft palate repair: two-stage closure versus one-stage closure. Cleft Palate Craniofac J 2010;47:623-30. doi: 10.1597/09-069.

[9] Koudoumnakis E, Vlastos IM, Parpounas K, Houlakis M. Two-flap palatoplasty: description of the surgical technique and reporting of results at a single center. Ear Nose Throat J 2012; 91:E33-7.

[10] Becker M, Hansson E. Low rate of fistula formation after Sommerlad palatoplasty with or without lateral incisions: an analysis of risk factors for formation of fistulas after palatoplasty. J Plast Reconstr Aesthet Surg 2013 ;66:697-703. doi: 10.1016/j.bjps.2013.01.031.

[11] Murthy J. Descriptive study of management of palatal fistula in one hundred and ninety-four cleft individuals. Indian J Plast Surg 2011 ;44:41-6. doi: 10.4103/0970-0358.81447. 
[12] Smith DM, Vecchione L, Jang S, Ford M, Deleyiannis FW, Haralam MA, et al. The Pittsburgh fistula classification system: A standardized scheme for the e description of palatal fistulas. Cleft Palate Craniofac J 2007;44:590-4. doi: 10.1597/06-204.1.

[13] Sunil Richardson, Nisheet A. Agni. Palatal Fistulae: A Comprehensive Classification and Difficulty Index. J Maxillofac Oral Surg 2014 ; 13: 305-309. doi: 10.1007/ s12663.013.0535-2.

[14] Campbell DA. Fistulae in the hard palate following cleft palate surgery. Br J Plast Surg 1962;15:377-84.

[15] Mukherji MM. Cheek flap for short palates. Cleft Palate Craniofac J 1969;6:415-20.

[16] Bianchi B, Ferri A, Ferri S, Copelli C, Sesenna E. Myomucosal cheek flaps: Aplication in intraoral reconstruction using three different techniques. Oral Surg Med Oral Pathoi Oral Radiol Endod 2009;108:353-9. doi: 10.1016/j.tripleo.2009.04.021.

[17] Guerrero-Santos J, Altamirano JT. The use of lingual flaps in repair of fistulae of the hard palate. Plast Reconstr Surg 1966;38:123-4.

[18] Rochrich RJ, Rowsell AR, Johns DF, et al. Timing of hard palatal closure: a critical long-term analysis. Plast Reconstr Surg 1996;98:236-46.
[19] Emory RE, Clay RP, Bite U, et al. Fistula formation and repair after palatal closure: an institutional perspective. Plast Reconstr Surg 1997;99:1535-8.

[20] Denny AD, Amm CA. Surgical technique for the correction of postpalatoplasty fistulae of the hard palate. Plast Reconstr Surg 2005;115:383-7.

[21] Carsten MH. Sequential cleft management with the sliding sulcus technique and alveolar extension palatoplasty. J Craniofac Surg 1999;10:503-18.

[22] Aldekhayel SA, Sinno H, Gilardino MS. Acellular dermal matrix in cleft palate repair: an evidence-based review. Plast Reconstr Surg 2012;130:177-82. doi: 10.1097/ PRS.0b013e318254b2dc.

[23] Agir H1, Eren GG, Yasar EK. Acellular Dermal Matrix Use in Cleft Palate and Palatal Fistula Repair: A Potential Benefit? J Craniofac Surg 2015 Jul;26(5):1517-22. doi: 10.1097/ SCS.000.000.0000001814.

[24] Diah E, Lo LJ, Yun C, Wang R, Wahyuni LK, Chen YR. Cleft oronasal fistula: A review of treatment results and a surgical management algorithm proposal. Chung Gang Med J 2007;30:529-37. 